\title{
DOES ATTACHMENT STYLE AND GENDER CORRELATE WITH SUBJECTIVE WELL-BEING AMONG MARRIED UNDERGRADUATES?
}

\author{
Kingsley Onyibor Nweke (PhD) \\ Department of psychology \\ Nnamdi Azikiwe University \\ Mail: ko.nweke@unizik.edu.ng \\ Dike Adannia Amarachukwu \\ Department of psychology \\ Nnamdi Azikiwe University \\ Mail: dannia_dyke@yahoo.com \\ Umeaku Ndubuisi Nkemakonam \\ Department of psychology \\ Nnamdi Azikiwe University \\ Mail: nn.umeaku@unizik.edu.ng \\ Anyaorah Godson Chukwudi \\ Department of psychology \\ Nnamdi Azikiwe University \\ Mail: gc.anyaorah@unizik.edu.ng
}

\begin{abstract}
The study examined the relationships between attachment style and gender as correlates of subjective well-being among married undergraduates. A total of 210 students from Sociology department in Nnamdi Azikiwe University Awka, participated in the study. Participants consist of 80 males and 130 females. Their age ranged from 18 to 30 years, with mean age of 22.00 years and standard deviation of 1.749. Two instruments were administered for data collection: the Experiences in Close Relationship-Revised (ECR-R) questionnaire which was developed by Fraley, R. C. and Shaver, P. R (2000). Also satisfaction with life scale which was developed by Dennier, E., Emmons, R.A., Larsen, R.J., \& Griffin, S., (1985). Statistics deployed was Pearson Moment Correlation Coefficient. Result show that the first hypothesis was not confirmed and the second hypothesis was not confirmed at $(r=.32, p>.05)$. Recommendations were made in line with research findings.
\end{abstract}

Keywords: Attachment Style, Subjective Well-Being, Gender 


\section{Introduction}

Improving human well-being is an inherent goal of the discipline of Psychology. Yet more often than it appears that most time married undergraduates seem to have things bothering them. This situation appears simple but if care is not taken may digress into serious health challenges that may to an extent challenge the foundation of essence in school. While some of these issues are detected earlier, others are not. More recently, it appears that the heart bit of individuals is to be happy. Yet, this goal appears to be a lofty idea to most persons. A closer look of this state seems to point at levels of sadness among married undergraduates. Perhaps, this state may lead gradually to psychological challenges such as depressions and anxiety. Scholars reported that lack of well-being among students has led to increase in levels of students depression and anxiety (Bedell, 2016; Mojtbai et al, 2016). Most often, married undergraduates appear to use the word I am not happy, or I am sad. These terms usually refer to the state of well-being one is in at a particular time. Well-being has been a concept that defines state of physical or psychological health. As a result well-being has implications to human existence. Since, the domain of Psychology is concerned with pursuit of both physical and psychological concerns of man; efforts in the direction of well-being are of great essence. In this study, the researchers are motivated to examine the relationship between type of attachment style and gender as correlates of subjective well-being among married undergraduates.

Subjective well-being is generally understood as "the level of well-being people experience according to their subjective evaluations of their lives" (Diener \& Ryan, 2009). The concepts "happiness", "life satisfaction" and "quality of life" are most commonly used as indicators for subjective well-being (Easterlin, 2001a; Howell \& Howell, 2008; Veenhoven, 1991). In fact, Subjective Well-being (SWB) covers the whole range of well-being, both positive and negative; it tends to be relatively stable over time, and is concerned with the internal subjective experiences of an individual (Diener etal, 1997). SWB differs from traditional measures of psychological health in that it takes account of personal life satisfaction and global happiness, rather than the identification of symptoms that represent deviations from the accepted norm for psychological health. However, individuals reporting psychopathology in terms of depression, anxiety and poor self-esteem also tend to report low SWB. It is a heterogeneous category that includes diverse phenomena such as optimism which relates to adaptive coping strategies, positive affect which is associated with protective psychosocial and behavioural factors, and life satisfaction (Dennier \& Chan, 2011). Accordingly, scholars argue that subjective wellbeing is divided in seven main determinants: demographics, socioeconomic status, health and functioning, personality, social support, religion and culture and geography and infrastructure (Das, Jone-Harreli, Nisha et al., 2020).

It appears that one construct that many researchers have linked to subjective wellbeing is attachment style. Attachment style or organization is a concept that derives from John Bowlby's attachment theory; it refers to a person's characteristic ways of relating in intimate care giving and receiving relationships with "attachment figures," often with one's parents, children, and romantic partners. The concept involves one's confidence in the availability of the attachment figure for use as a secure base from which one can freely explore the world when not in distress as well as a safe haven from which one can seek support, protection, and comfort in times of distress. Exploration of the world includes not only the physical world but also relationships with other people and reflection on one's internal experience. 
Few researchers have provided empirical evidence for support of the idea that adult attachment contributes to a sense of well-being. For example, adult attachment security was positively related to positive effect (Torquati \& Raffaelli, 2004) and well-being (La Guardia et al, 2000). For example, some individuals experience high levels of subjective well-being despite their adverse living situations. Others, however, experience a low level of well-being despite having certain outward advantages such as wealth, education, and good health (Seligman \& Csikszentmihalyi, 2000). People who have secure attachment styles usually express greater satisfaction with their relationships than people who have other attachment styles. For instance marital satisfaction has been found to be higher for securely attached spouses and for those whose partners reported more beneficial care-giving (Feeney, 1994). Similarly, people who report more parental rejection and less parental support, less family warmth and harmony, and more adverse childhood events may be more insecurely attached. Furthermore, research shows that insecurely attached adults are less satisfied about themselves, their current relationships and their life in general.

Most studies agree that attachment security is a stable trait that has persisting effects on other aspects of psychosocial functioning. However, some studies have revealed variations in attachment security following major life transitions and stressful events (Davila \& Sargent, 2003). Baldwin and Fehr (1995) demonstrated that $30 \%$ of people change their self-rated attachment style over a period of months. Moreover, Mikulincer and Shaver (2007) have noted that although attachment security is conceptualized as a stable trait, it is rooted in a complex cognitive network that includes many different context-related and relationshipspecific attachment representations. In fact, research shows that a person's sense of attachment security can change (Mikulincer \& Shaver, 2001). As attachment styles have been learned, they can be unlearned. Over time attachment styles can and do change (Baldwin \& Fehr, 1995) and they continue to be shaped by the experiences (Carnelley \& Janoff-Bulman, 1992). In this regard, a painful breakup of a relationship can make an earlier secure person insecure, and a happy relationship can make an avoidant person less so avoidant (Kirkpatrick \& Hazen, 1994). Study show that as many as a third of us may encounter real change in our attachment styles over a two-year period (Fuller \& Fincham, 1995), and it has been suggested that the avoidant and ambivalent styles are more likely to change than a secure style (Davila etal, 1997). A study by Waters et al (2000) confirmed the notion that throughout childhood, attachment representations remain open to revision in light of real experience. Perhaps the most important conclusion to this review is that collaborations across disciplines in research on adult attachment are vital at this point and provide many exciting opportunities for research investigating methodological and theoretical issues, particularly developmental processes and mechanisms which connect basic processes. Scholars have linked relationship between gender and subjective well-being with mixed results.

Gender is assumed to be a state of being male or female. Given widespread interest in gender and well-being, gender differences in SWB have been repeatedly examined over time. In a landmark review of the SWB literature, Wilson (1967) concluded that one's sex was not associated with happiness - though this conclusion was based on only two studies. Some researchers reported that men have significantly higher levels of SWB than women (Stevenson \& Wolfers, 2009; Haring et al, 1984), other studies have shown that women have significantly higher levels of SWB (e.g., Fujita et al, 1991). Complicating matters further, many studies have found no significant differences (Okun \& George, 1984), particularly after controlling for other relevant demographic factors (e.g., age, marital status) (e.g., White, 1992; Inglehart, 1990; Shmotkin, 1990; Warr \& Payne, 1982; Larson, 1978). 
It has been proposed that these inconsistent and conflicting reports are in part due to SWB being comprised of three components: (1) positive affect, (2) negative affect, and (3) life satisfaction (Dennier,et al, 2002). The magnitude and direction of the gender differences diverge for each component and conflating them in the analysis may reduce any observed differences - or it may lead to empirical confusion when not distinguished conceptually (Dennier, et al, 1999; Parker \& Brotchie, 2010). The idea that there are differences within these components has been supported by several studies that have examined the components of SWB independently. For instance, Lucas and Gohm (2000) found that in most of the nations examined, women experienced more negative affect than men. Other studies have reported similar findings that negative affect are more prevalent among women (NolenHoeksema \& Rusting, 2003). This is supported by research within the clinical domain that has found women experience greater levels of depression, anxiety, and mood disorders than men (Grant \& Weissman, 2007). Furthering the support of this explanation is the fact that women are also reported to experience higher levels of positive affect, or happiness, than men (Lee et al, 1991). Since attachment style and gender has been one of the major factors in subjective well-being which has implications to human health. Studies reveal that literature may have been in abundance with respect to married population, however dearth among students. If well-being is a concept to be reckoned with in among individuals, then irrespective of age every demographic deserves an examination of factors responsible in subjective well-being.

In a related study, Abdülkadir and Tansu (2010) examined the relationship between attachment style, subjective well-being, happiness and social anxiety among university students. Using 305 students who were studying in Eskisehir Osmangazi University, they found that there is a significant positive correlation between subjective well-being and happiness in relationship. In addition, preoccupied, fearful and dismissing attached students' social anxiety level is higher than secure attached students' social anxiety level. Similarly, Ali and Bagher (2011) examined the relationship between attachment styles and life satisfaction in high school administrators. In their study 88 high school administrators (43 men and 45 women) at the City of Tabriz in Iran were voluntarily selected. Found that life satisfaction of high school administrators can be predicted from the magnitude of their quality of attachment. Moreover, data revealed that high school administrators with anxious attachment were lower in life satisfaction than individuals with a secure attachment style. Individuals who could depend on attachment (dependability of others) on their couples and find them available were higher in life satisfaction. Wei et al (2011) examined attachment, selfcompassion, empathy, and subjective well-being among college students and community adults. Specifically, the examined whether the association between attachment anxiety and subjective well-being was mediated by Neffs (2003a, 2003b) concept of self-compassion. It also examined empathy toward others as a mediator in the association between attachment avoidance and subjective well-being. In Study 1, 195 college students completed self-report surveys. In Study 2, 136 community adults provided a cross-validation of the results. As expected, across these 2 samples, findings suggested that self-compassion mediated the association between attachment anxiety and subjective well-being, and emotional empathy toward others mediated the association between attachment avoidance and subjective wellbeing. Kaprale (2014) examined the relationship between adult attachment styles, selfesteem, jealousy and satisfaction with life. Using 107 participants, she reported that individuals with secure attachment style are higher on self-esteem levels and satisfaction with life than insecure attachment style and a positive relationship was found between the levels of self-esteem and satisfaction with life. However, secure and insecure attachment styles did not 
show any difference on feelings of jealousy and it was found that satisfaction with life increases when levels of jealousy decrease. Haring et al (1984) examined studies from the US that examined gender and social class as predictors of subjective well-being. The studies included were conducted prior to 1980 and had to include "life satisfaction, happiness, morale, quality of life, and subjective well-being" as keywords. Based on the studies that met the above criteria, their results showed that men had slightly higher levels of subjective wellbeing, which included life satisfaction, than women, but the magnitude of this difference was small $(r=.03 ; d=.06)$. Wood et al (1989) conducted another meta-analysis on sex differences in positive well-being with attention paid to marital status and emotional style. They drew upon 85 studies from both US and international samples that provided a comparison between men and women on measures of life satisfaction, happiness, morale, positive affect, or general well-being. In terms of life satisfaction, it was found that men had lower levels of life satisfaction than women $(d=-.03)$.

Pinquart and Sorensen (2001) in their meta-analysis study, investigated differences between men and women over the age of 55 in psychological well-being. They included 174 studies from the developmental literature that looked at gender differences in life satisfaction. They used 58 studies to investigated differences between men and women over the age of 55 in happiness. They found that older women, as compared to older men, reported slightly lower levels of happiness. Earlier studies focused on relationship between attachment style, subjective well-being, happiness and social anxiety (Abduikadir \& Tansu, 2010), attachment style and life satisfaction (Ali \& Bagher, 2011), attachment, self-compassion, empathy and well-being (Wei et al 2011) and adult attachment, self-esteem, jealousy and satisfaction with life (Kaprale, 2014). Also, other studies focused on gender and social class (Haring, et al 1984; meta-analysis on sex differences in positive well-being (Wood et al, 1989), and differences between men and women in psychological well-being (Pinquart \& Sorensen, 2001). On these earlier studies and dearth of knowledge in the present variables rest the motivation of the researchers to unravel the possible relation between attachment securities, and gender on subjective well-being among married undergraduates.

\section{Hypotheses}

1. Type of attachment style will positively and significantly correlate with subjective well-being of married undergraduate students.

2. Gender will positively and significant correlate with subjective well-being of married undergraduate students.

\section{Theoretical Framework}

The variables of this study attached to the theory of Bowlby 1969. According to the theory, attachment may not be mutual. Attachment style refers to the degree of security an individual feels in a relationship. The individual that feels security learns two major types of attitude: attitude about self, which is self-esteem, and attitude about others, inter-personal trust. According to Bowlby, both attitudes emerge in early years of an individual's development. Therefore, married under graduates who had caring caregivers at infant carry such attitude to later life events, while those who did not also carry low self-esteem and lack of interpersonal trust to adulthood. Gender in the context of the present study, is a state of being a male or a female. Therefore at birth individual emerge with either status. Attachment style appears to be a sub component of Subjective wellbeing. This assumption comes because individuals emerge with self-esteem and inter-personal trust or lack of both. As a result of such 
development, the state of happiness which is the hallmark of subjective wellbeing appears to be a yard stick for degree of joy and happiness one feels. On this basis, attachment style is adopted as the theoretical framework for this study.

\section{METHOD}

\section{Participants}

The participants employed in this study were two hundred and ten regular students from department of sociology, Nnamdi Azikiwe University, Awka. The participants were randomly selected using simple random sampling. Two hundred and ten students participated in the study. Among these participants were 80 males and 130 females. Their age ranged from 18-30 years, they had a mean age of 22.00 and standard deviation of 1.749. All the participants are undergraduates from the same department, their religion were Christians and all were drawn from 100 levels to 4001evel.

\section{Instruments}

Two instruments were used to collect data for the present study. They include; the experiences in close relationships-revised (ECR-R) questionnaire, it was developed by Fraley, R.C, and shaver, P.R(2000);it is a 36-item scale that measures adult attachment style. The scale has two levels of attachment; avoidant and anxiety attachment levels. Item 1 to 18 measures anxiety attachment level among people, while item 19 to 36 measures avoidant attachment level among people. Higher score indicates or represents high anxiety and except item 9 and 11 that have reverse scoring; i.e higher score represents low anxiety rather than high anxiety. The second scale is satisfaction with life scale which was developed by Dinner, E, Emmons, R.A., Larsen, R.J, \& Griffin S. This is kept on a continuous scoring and it has some cut-offs as the benchmarks to be used, examples 31-35= Extremely Satisfied, 2630=Satisfied, 21-25-Slightly Satisfied, 20=Neutral, 15-19=Slightly Dissatisfied, 1014=Dissatisfied and 5-9- Extremely Dissatisfied. The 5-item scale has a reliability of 0.88 Cronbach alpha reliability coefficient, which was conducted in another study last year.

\section{Procedure}

The researchers ensured that that the consents of the participants were secured before the commencement of the study. The participants were selected using probabilistic sampling technique. Firstly, one faculty was selected from nine (9) faculties of the institution. Therefore one department was selected from one (1) faculty. The research instruments (questionnaires) were administered to the participants individually. They were instructed on how to fill the questionnaires and were encouraged to do so honestly. After the participants responded to the instrument, the questionnaires were collected back immediately. Two hundred and eighty (280) questionnaires were administered, and 210 well-filled forms were recovered.

\section{Design and statistics}

Correlational design and Pearson product moment correlational coefficient was used to manage the data. At the end, the data from questionnaires were subjected to data analysis using statistical package for social science version 20.0 (SPSS). 


\section{RESULT}

Table 1: descriptive statistics

\begin{tabular}{llll}
\hline & Mean & Std. Deviation & N \\
\hline GENDER OF PARTICIPANTS & $\mathbf{1 . 6 7}$ & $\mathbf{. 4 7 1}$ & $\mathbf{2 1 0}$ \\
ANXIETY ATTACHMENT STYLE & $\mathbf{8 3 . 3 0}$ & $\mathbf{4 . 1 6 3}$ & $\mathbf{2 1 0}$ \\
AVOIDANT ATTACHMENT STYLE & $\mathbf{6 9 . 5 7}$ & $\mathbf{5 . 6 9 6}$ & $\mathbf{2 1 0}$ \\
SUBJECTIVE WELL-BEING & $\mathbf{2 2 . 0 0}$ & $\mathbf{1 . 7 4 9}$ & $\mathbf{2 1 0}$ \\
\hline
\end{tabular}

Table 2: below, shows summary of correlation between attachment style (anxiety and avoidant), gender and subjective wellbeing.

\begin{tabular}{lllll}
\hline & Gender & $\begin{array}{c}\text { Anxiety } \\
\text { attachment }\end{array}$ & $\begin{array}{c}\text { Avoidance } \\
\text { attachment }\end{array}$ & Subjective well being \\
\hline $\begin{array}{l}\text { Gender } \\
\begin{array}{l}\text { Anxiety } \\
\text { Attachment }\end{array}\end{array}$ & .175 & 1 & & \\
$\begin{array}{l}\text { Avoidance } \\
\begin{array}{l}\text { Attachment } \\
\text { subjective well } \\
\text { Being }\end{array}\end{array}$ & .064 & .059 & 1 & \\
\end{tabular}

\section{Correlation is significant at .05}

The table above shows a positive but not significant relation between anxiety attachment style and subjective wellbeing $(r=.18, \mathrm{P}>.05)$, also negative and no significant correlation was found between avoidant attachment style and subjective wellbeing $(r=-.06, \mathrm{P}>.05)$. Finally, the table revealed positive and no significant correlation between gender and subjective wellbeing $(r=.32,>.05)$. This means that been male or female has nothing to do with subjective well-being.

\section{DISCUSSION AND CONCLUSION}

Does attachment style and correlate with subjective wellbeing of married undergraduates? Empirical result revealed that hypothesis one was not confirmed. Thus, attachment style does not correlate with subjective wellbeing. This implies that the type of attachment that married undergraduate has, may not relate to degree of happiness, joy, or any indicator of satisfaction the undergraduate may feel. This finding goes a bit centrally to earlier reports (Abdulkadir \& Tansu, 2010; Ali \& Bagher, 2011). For example, Kaprale (2014), reported that secure attachment style enhances high self-esteem levels and satisfaction with life than insecure attachment style. The variation in the present study may have been as a result of cultural differences. For instance, most of earlier studies were done in western and Asian cultures. However, theoretical explanation to this variation may found in the attachment theory by Bowlby (1969). According to the theoretical assumptions of the attachment theory, 
attachment may not have to be mutual, which means that both parties may not feel the security part of attachment at the same degree. For instance, in the present culture, parent and early care-givers may not pay attention to the type attitude their pattern relationship with the newly born infant was developing. To this end most care-givers end up developing in the newly born insecure attachment style. As the newly born infant grows and develops, she already knows that there is no trust for others, and lives life generally with low self- esteem. Such an adult may be sceptical about relationship with others in most areas of her or his life. As a matter of fact, emotional relationship becomes a cultural demand by his or her close relatives at a certain age. Now, the perception of the young adult becomes to fulfil an integral part of culture in which he or she lives. Therefore, expectations from the relationship are not a matter to struggle with because there is no expectation in the first place. In other words, this young adult lives life as though it is more like a routine than a design for happiness and greater fulfilment. Although, scholars reported that attachment may be steady over time in course of growth and development. In the present context family pressure, friends advice, and societal demands become so persuasive that individuals prefer to keep in the insecure attachment security than they seek ways of enhanced marital satisfaction.

Furthermore, the present study did not confirm significant correlation between gender and subjective well-being. However, earlier studies found positive and significant correlation between gender and happiness (Pinquart \& Sorensen, 2001; Wood, et al 1989; Haring et al, 1984). According to Chung and Hahn (2020), men report higher levels of subjective wellbeing than women. Again in the present discrepancy, earlier works were done outside the present culture, therefore perception or conceptual implication of gender may have different connotations. For instance, in the present culture there is distinction between gender roles, therefore each partner is expected to perform a specific role. This perception may differ with respect to Asian and western cultures. As result of studies done in those locations may not be confirmed in the present culture. However, the theoretical explanation may be found in the attachment theory. For instance Bowlby argues that attachment may not be mutual between the care-giver and the and newly born. Therefore this assumption may provide a clue for gender difference in attachment security. However, due to cultural influences it may be argued that since both couple were raised in the same culture, cultural norm may have established a base for the manifestation of subjective well-being.

\section{Limitation of Study}

The major limitation in the present study was the sample size and the study participants. For instance, the study focused on married undergraduates alone.

\section{Recommendation}

The researchers recommend that more studies should be carried out on subjective well-being among undergraduates in both married and unmarried status. Also, wider studies in a large capacity that may involve other cultures within the locality. Newly married parents may have to undergo training in attachment theory to enlighten them about implications of type of attachment and personality manifestations in later life events. Those married undergraduates may have to attend programme to make them understand their present behaviours with the aim of modifying their behaviours thereby enhancing subjective wellbeing. 


\section{REFERENCES}

Ainsworth, M. D. S., Blehar, M. C., Waters, E., \& Wall, S. (1978). Patterns of attachment: A psychological study of the Strange Situation. Hillsdale.

Andrews. F., \& Withey. S., (1976). Social indicators of well-being: American perceptions of quality of life. Plenum press.

Archer.J., (1996). Sex differences in social behaviour are the social role and evolutionary explanations. Compatible? American psychologist, 51, 9, 909-917.

Argyle.M., (1987). The psychology of happiness, Methuen.

Baldwin. M. W., \&Fehr. B., (1995). On the instability of attachment style rating. Personal relationship.https://doi.org/10.1111/j.1475-6811.1995.tb00090.x

Bowlby, J. (1969). Attachment and Loss, Vol. 1: Attachment. Attachment and Loss. Basic Books.

Bradburn, N. M., \& Caplovitz, D. (1965). Reports on Happiness. A Pilot Study of Behavior Related to Mental Health. Aldine Publishing Company.

Brickman, P., \& Campbell, D. T. (1971). Hedonic relativism and planning the good society. In M. H. Appley (Ed.), Adaptation-level theory (pp. 287-305). Academic Press.

Brief, A.P., Butcher. A.H., Genige. J, M., \&Link. K.E., (1993). Integrating bottom-up and top down theories of subjective well-being: the case of health. Journal of Personality and Social Psychology, 64 (4), 646-653.

Carnelley. K .B., \& Janoff- Bulman. R. (1992). Optimism about love relationship; General vs specific lessons from one's personal experience. Journal of social and personal relationships, 9, 5-20.

Chung, H. Y. \& Hahn, Y. (2020). Work transitions, gender, and subjective wellbeing. Applied research in quality of life (2020). https://doi.org/10.1007/s11482-020-09860-z

Coburn, D., (2004). Beyond the income inequality hypothesis: class neo- Liberalism, and health inequalities. Social science and medicine, 58, 1, 41-56.

Costa, P. T., \& McCrae, R. R. (1984). Personality as a Lifelong Determinant of Well-Being. In C. Malatesta, \& C. Izard (Eds.), Affective Process in Adult Development and Aging (pp. 141-157), Sage.

Davila .J., Burge.D., \& Hammen, C. (1997), Why does attachment style change? Journal of personality and social psychology 72 (4), 826-838.

Davila. J., \& Sargent. (2003). The meaning of life (events) predicts changes in attachment security. Personality and social psychology bulletin, 29, 1383-1395.

Dennier, E., Suh, E. M., Lucas, R. E., \& Smith, H. L. (1999). Subjective well-being: three decades of progress, Psychological Bulletin, 125, 276-302.

Dennier; E. \& Ryan. K. (2009). Subjective well-being: A general overview. South AfricanJournal of Psychology. 39 (4):391-406.

Dennier; E., Suh. E., \&Oshi.S., (1997). Measuring the quality of life: Economic, social, and subjective indicators, Social Indicators Research, 40, 189 -216.

Dennier; E., \& Chan. M.Y, (2011). Happy people live longer: subjective well-being contributes to health and longevity.https://doi.org/10.1111/j.1758-0854.2010.01045.x

Dennier; E., (1984). Subjective well-being. Psychological bulletin. 95 (3), 542- 575.

Dennier; E., Emmons. R.A., Larsen. R.J., \& Griffen. S., (1985). The satisfaction with life scale. Journal of per life scale. Journal of personality Assessment, 49, 71- 75.

Dennier; E., Lucas. E.R., \& Oishi. S., (2012). Subjective well-being: The science of happiness and life satisfaction.DOI:10.1093/oxfordhb/9780195187243.013.0017 
Dennier, E., Lucas.R.E \& Oishi. S., (2002). Subjective well-being, the science of happiness and life satisfaction. In C. R. Snyder \& S.J. Lopez (Eds). Handbook of positive psychology.

Easterlin, R. A. (2001). Building a better theory of wellbeing.DOI: 10.1093/0199286280.003.0002

Easterlin. R. A., (1974). Does environment growth improve the human lot? Some empirical evidence-'In Nations and Households in economic Growth: 85- 125.

Fagot.B.I., \& Leinbach. M.D., (1981). A schematic processing model of sex typing and stereotyping in children. Child development, 52 (4), 1119-1134

Feeney. J.A., (1994) Attachment style, communication patterns and satisfaction across life cycle of marriage. Personal relationship, 1, 4,333- 348,

Feist. G.J., Bodner. T.E., Jacobs. J.F., \& Miles (1995). Integrating top-down and button-up structural models of subjective well-being. A longitudinal investigation, Journal of personality \& social psychology. 68 (1), 138- 150.

Fonagy. P., Steele,H., \& Steele. M., (1991). Material representations of attachment during pregnancy predict the organization of infant - mother attachment at one year of age. Child development 62, 891-905.

Fujita. F, Diener. E., \& Sandulk. E., (1991). Gender differences in negative affect and wellbeing- The case for emotional intensity. Journal of personalityand social psychology, 61(3), 427-434.

Fuller. T.L., \& Fincham. F.M., (1995). Attachment style in married couples: Relation to current martial functioning, stability over time, and method of assessment. Personal relationships, 2 (1), 17-34.

Grant. B.F., \& Wesisman. M.M., (2007). Gender and the prevalence of psychiatric disorders in N.E. Narrow, M.B. First, P.J. Sirovatka P J, D.A Regier (Eds). Age and gender considerations in psychiatric diagnosis. A research agenda for DSM.

Gurin.J., Veroff. J., \& Felds. S., (1960). Americans view their mental health. Basic books.

Howell. R.T., \& Howell. C.J., (2008). The relation of economic status of subjective wellbeing in developing countries; A meta-analysis. Psychological bulletin, 134, 536-560.

Huston. A. C., (1983). Sex typing. In E.M. Hetherington (ed). Handbook of child psychology: socialization, personality, and social development (pp 387-467).

Inglehart. R., (1990). Culture shift in advanced industrial society. Princeton university press,

Larson. R., (1978). Thirty years of research on subjective well-being of older Americans. Journal of Gerontology, 33, 1, 109-125.

Lee. G.R., Seccombe. K., \& Shehan; C.L., (1991). Marital status and personal happiness: An analysis of trend data. Journal of marriage and the family.

Lucas. R.E., \& Gohm. C.L., (2000) Age and sex difference in subjective well-being across cultures.

Main, M., \& Hesse, E. (1990). Parents' unresolved traumatic experiences are related to infant disorganized attachment status: Is frightened/frightening parental behavior the linking mechanism? In M. T. Greenberg, D. Cicchetti, \& E. M. Cummings (Eds.), Attachment in the preschool years: Theory, research, and intervention (pp. 161182), University of Chicago Press.

Main, M., \& Solomon. J., (1986). Discovery of a new, insecure- disorganized / disoriented attachment pattern. In T.B Brazelton \& M. Yogman (eds), affective development in infancy,(pp. 95-124).

Marcus, H., Crane. M., Berstein. S., \& Siladi. M., (1982). Self - schemas and gender. Journal of personality and social psychology, 42, 38-50. 
Martin. C.L., \&Little. J.K., (1990). The relation of gender to children's sex typed preferences and gender stereotypes. Child development, 61, 1427-1439.

Martin. C.L., (1991). The role of cognition in understanding gender effects. In W.R. Hayne (ed), advances in child development and behaviour (vol 23,) pp 113- 149.

Michalos. A.C., (1985). Mutiple Discrepancies theory (MDT). Social indicators research, 16, 347- 413.

Mikulincer. M., \& Shaver. P.R., (2001). Attachment theory and inter group bias. Evidence that priming the secure base schema: attenuates negative reactions to out- groups. Journal of personality and social psychology, 81 (1),97-115.

Okun. M.A., \& George. L.K., (1984). Physician - and self- ratings of health, neuroticism and subjective well-being among men and women. Personality and subjective wellbeing.10.1016/0191-8869(84)90027-8

Parker. G., \& Brotchie. H., (2010). Gender differences in depression. International review of psychiatry, 22(5), 429-36.

Ruble. D.N., Sc Martin. C.L., (1998). Gender development in W.Damon (eds)., Handbook of child psychology (5th Ed., Vol.3, pp. 933-1016). New york: wiley.

Ryff. C.D., (1989). Happiness is everything or is it explorations on the meaning of evdaimonic well-being. Journal of personality and social psychology, 57,1069-1081.

Seligman. M.E.P., \& Csikszentmihalyi. M., (2000). Positive psychology: An introduction. American psychologist, 55, 5-14.

Seligman, M.E.P., (2003). Authentic Happiness using the new positive psychology to realize your potential for deep fulfilment. Nicholas Brealey.

Serbin, L.A., Powlishta, K.K., \& Gulko, J., (1993). The development of sex typing in middle childhood. Monographs of the society for research in child development, 58 (232).

Shmotkin, D., (1990). Subjective well-being as a function of age and gender. A multivariate look for differentiated trends. Social Indicators Research, 23, 201-230.

Slaby, R.G., \& Frey .K.S., (1975). Development of gender constancy and selective attention to same. Sex models child development 52, 849-856.

Sroufe, L.A., (1985). Attachment classification from the perspective of infant - caregiver relationship and infant temperament. Child development,56, 1- 14.

Stevenson, B., \& Wolfers .J., (2009). The paradox of declining female happiness. American Economic Journal: Economic Policy, 1, 2, 190-225.

Thompson. S.K., (1975). Gender labels and early sex role development. Child development, 46, 339- 347.

Torquati. J. C., \& Raffaelli. M., (2004). Daily experiences of emotions and social contexts of securely and insecurely attached young adults. Journal of adolescent research, 19, 740- 758.

Veenhoen, R, (1988). The utility of happiness.Social Indicators Research, 20, 333-354.

Veenhonven,R. (1991). Handbook of social indicator and quality of life research, 63-77.

Warr, P., \&Payne. R., (1982). Experience of strain and pleasure among British adults. Social Science and Medicine, 16(19), 1691-1697.

Waters, E., Merrick. S., Treboux. D., Crowell. J., \& Albersheim. L., (2000). Attachment security in infancy and early adulthood: a twenty - year longitudinal study.doi: 10.1111/1467-8624.00176.

Watson. D., Clark. L., \& Tellegen. A., (1988). Development and validation of brief measures of positive and negative effect. The PANAS scales. Journal of Personality and Social Psychology, 54, 1063-1070. 
White. J. M., (1992). Marital status and well-being in Canada. Journal of family issues, 13, 390-409.

Wilson .W. (1967). Correlates of allowed happiness. Psychological bulletin, 67, 294-306.

Wilson. W., (1967). Correlates of Avowed Happiness. Psychological bulletin, 67 (4), 294306. Doi: 1037/h0024431.

Kirti, V. D., Jone-Harrell, Carla, Botchwey et al (2020). Understanding subjective wellbeing: perspective from psychology and public health. Public health Rev, 14, 25 